\title{
Investigation of the behaviour of single span reinforced concrete historic bridges by using the finite element method
}

\author{
S. B. Yuksel \\ Department of Civil Engineering, Selcuk University, Turkey
}

\begin{abstract}
Single span reinforced concrete (RC) historic bridges have been commonly constructed with symmetric parabolic haunches. Due to their non-prismatic geometrical configuration, their assessment, particularly the computation of fixed-end forces (FEFs) and fixed-end moments (FEMs), becomes a complex problem. Therefore, the aim of this study is to investigate the modelling, analysis and behaviour of such bridges with the aid of finite element (FE) modelling. FEFs and FEMs due to uniformly distributed loads and point loads, as well as vertical deflections, were computed through a comprehensive parametric study. Design formulas and dimensionless design coefficients were proposed based on a comprehensive parametric study using FE models.
\end{abstract}

Keywords: historic bridge, non-prismatic member, finite element analysis, parabolic haunch, stiffness factor, fixed-end force.

\section{Introduction}

Bridges and buildings often contain non-prismatic members, which are identified with a varying depth along their span lengths. In these members, linear or parabolic height variations are commonly preferred to lower the stresses at the high bending moment regions and to maintain the deflections within acceptable limits. As depicted in fig. 1, in general, the single span reinforced concrete (RC) historic bridges have symmetrical parabolic haunches with constant haunch length ratio $(\alpha)$ of 0.5 and varying haunch depth ratio (R) (see fig. 2 for detailed description of $\alpha$ and R).

In 1958, Portland Cement Association issued the "Handbook of Frame Constants" [1] including a series of tables containing stiffness factors, carryover 
factors and FEM coefficients for commonly used non-prismatic members. These factors have been used in conventional methods since 1958 for the analyses of non-prismatic members [2, 3]. The results of finite element (FE) analyses performed by El Mezaini et al. [4] and Balkaya [5] proved that FEMs, bending stiffness factors and carry-over factors for non-prismatic members given in PCA [1] involve significant errors, especially for deep haunches.

The purpose of this study is to investigate the behaviour of single span RC historic bridges with symmetrical parabolic haunches under vertical forces. In this conjunction, the present study carried out many FE analyses for various single span RC historic bridges. Alternatively, this study proposed formulas and estimator coefficients computed by a parametric study using two-dimensional FE models. By using the proposed approach, the evaluation of single span RC historic bridges can be achieved without necessitating any detailed FE solutions. In addition, robust FE analyses results allowed the examination of the sources and magnitudes of errors during the conventional analysis.

\section{Parametric study and finite element modelling}

The geometric parameters of the typical single span historic bridge with parabolic haunches are presented in fig. 2; where, $\mathrm{L}$ is the span length, $\mathrm{b}$ is the width, $\mathrm{h}$ is the mid-span depth or smallest depth, $\alpha$ is the haunch length ratio (haunch length divided by the total length of the member) and $\mathrm{R}$ is the haunch depth ratio.
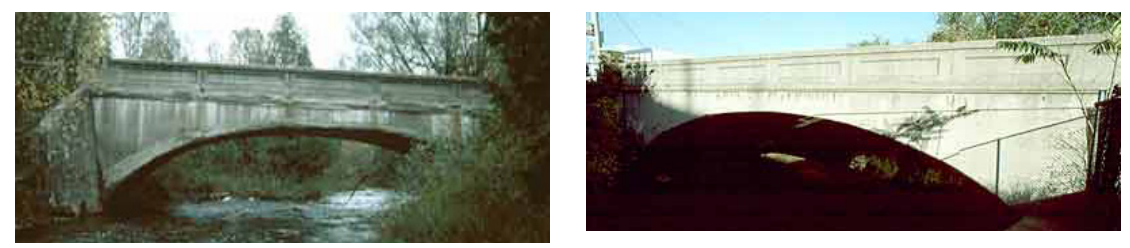

Figure 1: Typical single span RC historic bridges having symmetrical parabolic haunches.

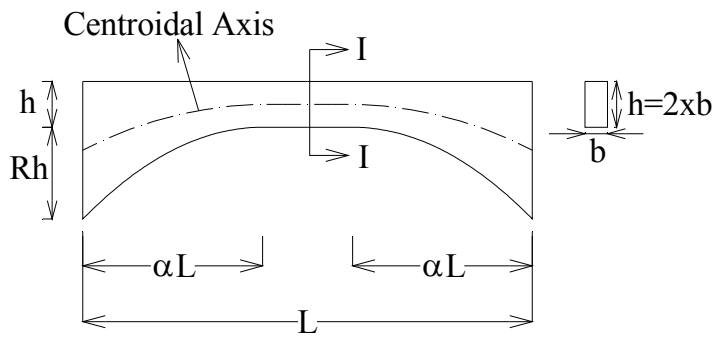

Figure 2: Geometric parameters of a typical single span historic bridges with parabolic haunches. 
In all of the analyses, the span lengths, widths and the mid-span depths of the single span historic bridges were respectively taken to be the constant values of $\mathrm{L}=10 \mathrm{~m}, \mathrm{~b}=0.5 \mathrm{~m}$ and $\mathrm{h}=1 \mathrm{~m}$ while the haunch depth ratios $(\mathrm{R})$ were changed. The modulus of elasticity (E) and the Poisson's ratio ( $v$ ) were taken as $3 \times 10^{7} \mathrm{kN} / \mathrm{m}^{2}$ and 0.2 , respectively. The parametric studies were performed considering a constant haunch depth ratio of $\alpha=0.5$ with varying $\mathrm{R}$ in the range of 0.0 to 4.0 with 0.1 increments. In all of the cases, the effects of shear deformations were considered, and fixed-end conditions were assumed at the supports.

The behaviour of single span RC historic bridges was investigated by developing two dimensional FE models using SAP2000 [6]. To produce benchmark results for FE analyses, four-node isoparametric plane-stress FEs with two translational degrees of freedom and one rotational degree of freedom per node were utilized. The typical FE models for single span RC historic bridges can be seen in fig. 3. In order to satisfy the adequate accuracy for the results of FE analyses, each single span historic bridge was sub-divided into 8000 elements.

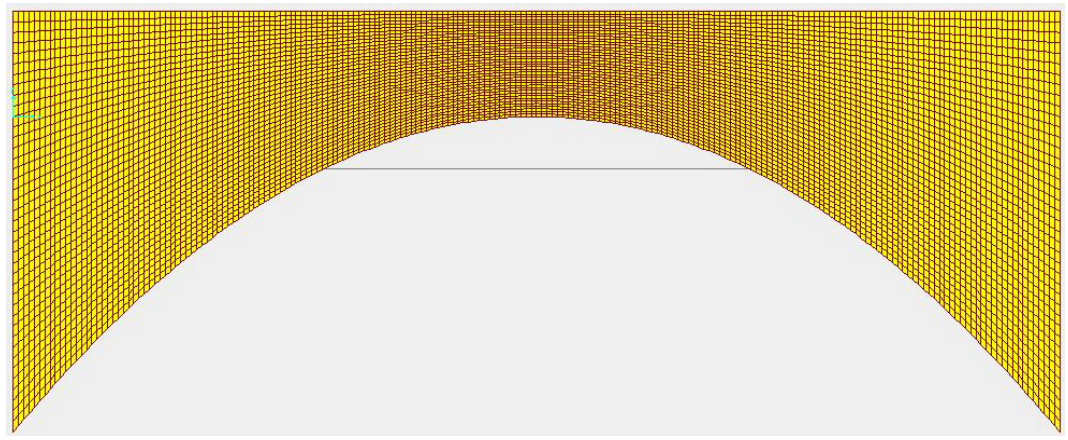

Figure 3: $\quad$ A typical FE mesh of a single span historic bridge.

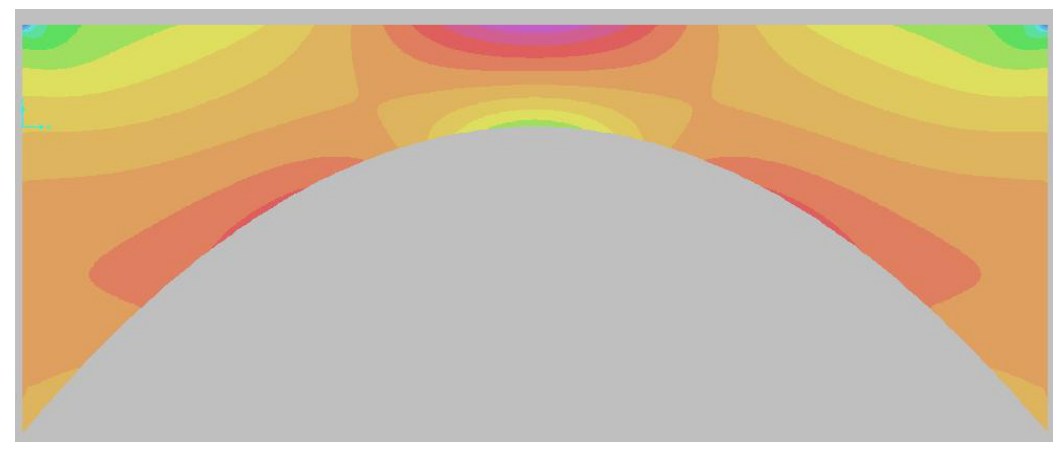

Figure 4: Axial stress contours due to uniformly distributed vertical load of $\mathrm{w}=1 \mathrm{kN} / \mathrm{m}^{2}$, which is obtained from FE analyses. 
The fixed-end forces (FEFs) and FEMs as well as mid-span vertical deflections of single span historic bridges due to vertical loadings were obtained by FE analyses. Fig. 4 shows axial stress contours of single span RC historic bridges $(\mathrm{R}=3)$ due to uniformly distributed vertical load $\left(\mathrm{w}=1 \mathrm{kN} / \mathrm{m}^{2}\right)$ at the top surface in which the maximum stress reaches to $0.70 \mathrm{kN} / \mathrm{m}^{2}$ at the mid-span. The computation of stress values or nodal forces is not sufficient for the calculation of the fixed-end reactions. Despite the robustness of the FE model, the generation of FEFs and FEMs from the nodal outputs of the detailed mesh still remains as an intricate task. FEFs and FEMs were calculated using the nodal force outputs of FE analyses proposed by Bathe [7] and applied by Horrowitz [8], Balkaya et al. [9], Yuksel [10], Yuksel and Arikan [11] and Yuksel [12]. A postprocessor was developed to sum the element nodal forces at the predetermined sections in order to be able to calculate the fixed-end reactions.

The results of FE analyses can be accepted as the real elastic values. The actual behaviour of non-prismatic members can be accurately simulated either with the FE models developed in this study or the previous FE studies [4, 5, 912]. The discontinuity of the centroidal axis, local stress concentrations, nonlinear stress distributions (see fig. 4) and the existence of null areas that reduces the member stiffness are taken into consideration in FE models. Since the stress concentrations, non-uniform stress distributions, the coupling between axial forces and moments cannot be considered in the classical beam theory, the approximate results obtained from the beam theory [1-3] deviated from the real elastic values.

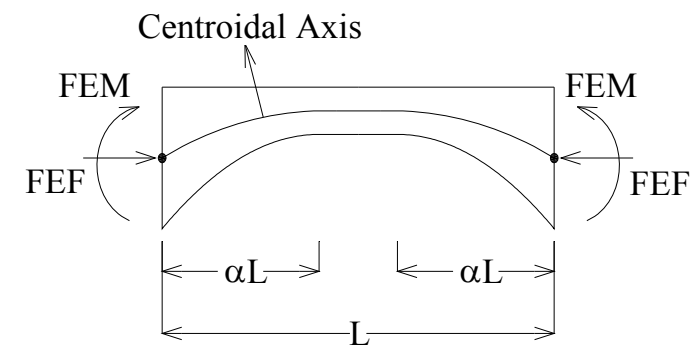

Figure 5: $\quad$ Fixed-end reactions of a single-span bridge historic bridges under the action of vertical forces.

\section{Results of parametric study}

FEFs and FEMs due to the uniformly distributed vertical load of $\mathrm{w}=1 \mathrm{kN} / \mathrm{m}^{2}$ at the top surface and the concentrated point load of $\mathrm{P}=10 \mathrm{kN}$ at the mid-span were obtained by using FE analyses. Fig. 5 illustrates the corresponding fixed-end reactions. Plots were presented for the variations in FEFs and FEMs as the functions of the haunch depth ratios (R). The results of the FE analyses performed to investigate FEF and FEM variations under the action of the uniformly distributed vertical load of $\mathrm{w}=1 \mathrm{kN} / \mathrm{m}^{2}$ at the top surface were 


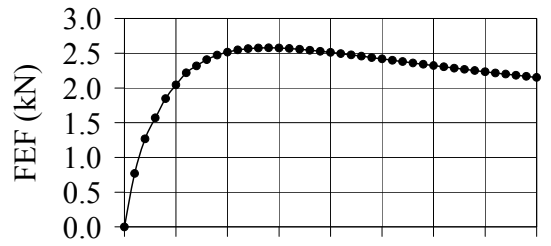

$\begin{array}{lllllllllll}0.0 & 0.5 & 1.0 & 1.5 & 2.0 & 2.5 & 3.0 & 3.5 & 4.0\end{array}$

(R)

(a)

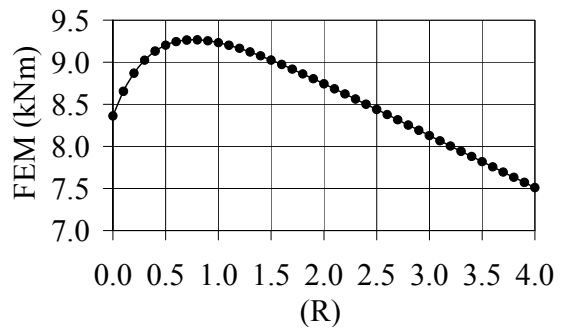

(b)

Figure 6: $\quad$ Variation of (a) FEF values and (b) FEM values with respect to $R$ under the action of uniformly distributed vertical load of $\mathrm{w}=1 \mathrm{kN} / \mathrm{m}$.

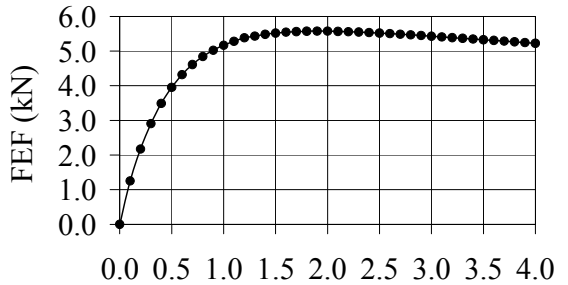

(R)

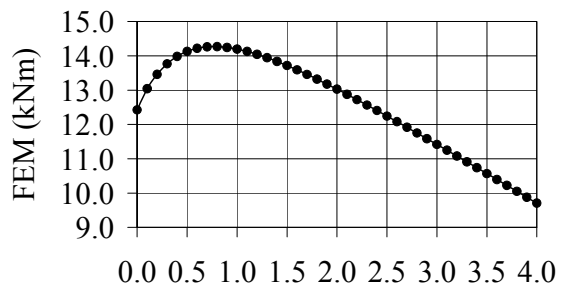

(R)

(b)

Figure 7: $\quad$ Variation of (a) FEF values and (b) FEM values with respect to $R$ under the action of concentrated point load of $\mathrm{P}=10 \mathrm{kN} / \mathrm{m}$ at the mid-span.

presented in fig. 6(a) and fig. 6(b), respectively. Likewise, fig. 7(a) and fig. 7(b) illustrate the typical variation of FEFs and FEMs under the action of concentrated point load $(\mathrm{P}=10 \mathrm{kN})$ at the mid-span, respectively. FEMs increase only for the ratios less than 0.8 , and then start to decrease for higher depth ratios.

FE element analyses proved that horizontal compressive forces (FEFs) occur at the ends of single span RC historic bridges due to vertical loadings. Because of arching action, the continuous change of centroidal axis orientation produces FEFs in addition to FEMs under vertical loading conditions, when the ends of the single span RC historic bridges are completely restrained. It is obvious that the continuous changes of the centroidal axis associated with the non-prismatic section causes strong coupling between bending moments and axial forces. The relationships between the FEF values and the haunch depth ratios are non-linear. The analytical approaches and the traditional beam theories often need to introduce assumptions to simplify the problem and yield an erroneous solution. Unless detailed FE modelling was applied, the conventional methods using frame elements will be deficient in computing these FEFs due to the progressive changes in the centroidal axis of the non-prismatic sections. FEF and FEM values presented in figs. 6 and 7 were provided numerically in table 1. 
Vertical mid-span deflections due to uniformly distributed vertical loadings $\left(\Delta_{\mathrm{W}}\right)$ and also vertical mid-span deflections due to concentrated point load at the mid-span $\left(\Delta_{\mathrm{P}}\right)$ were separately obtained using FE analyses. Fig. 8(a) shows the mid-span vertical deflections $\left(\Delta_{\mathrm{W}}\right)$ due to uniformly distributed vertical loadings of $\mathrm{w}=1 \mathrm{kN} / \mathrm{m}^{2}$ versus haunch depth ratios $(\mathrm{R})$. Typical variation of the vertical mid-span deflections $\left(\Delta_{\mathrm{P}}\right)$ due to concentrated point load at the mid-span $(\mathrm{P}=10 \mathrm{kN} / \mathrm{m})$ is presented in fig. $8(\mathrm{~b}) . \Delta_{\mathrm{W}}$ and $\Delta_{\mathrm{P}}$ values decrease as the haunch depth ratios $(\mathrm{R})$ are increased. The relationships of $\Delta_{\mathrm{W}}$ and $\Delta_{\mathrm{P}}$ values with the haunch depth ratios are non-linear.

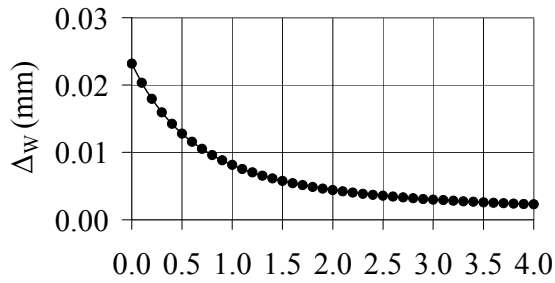

(R)

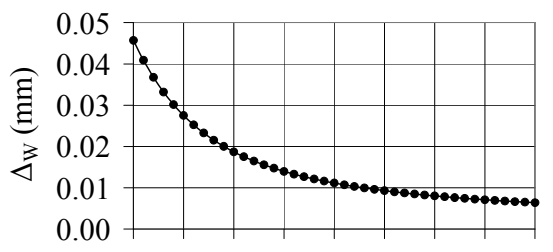

$\begin{array}{llllllllll}0.0 & 0.5 & 1.0 & 1.5 & 2.0 & 2.5 & 3.0 & 3.5 & 4.0\end{array}$

(a)

Figure 8: Variation of vertical mid-span deflections under the action of (a) uniformly distributed vertical load of $\mathrm{w}=1 \mathrm{kN} / \mathrm{m}^{2}$ and (b) concentrated point load of $\mathrm{P}=10 \mathrm{kN}$ at the mid-span.

It is demonstrated that the fixed-end support reactions and mid-span deflections for the single span RC historic bridges under vertical loading conditions are greatly influenced by the geometric parameter, R. Thus, they are important in the arch formation and affect the location of arch height, axial thrust values, bending moments and mid-span deflections.

\section{Design formulas and empirical design coefficients}

Design equations and the design coefficients were developed based on the results of the extensive parametric studies which are carried out for the single span RC historic bridges analysing two-dimensional plane stress $\mathrm{FE}$ models. Each of the dimensionless estimation coefficients, $\mathrm{FC}_{(\mathrm{W})}, \mathrm{MC}_{(\mathrm{W})}, \mathrm{FC}_{(\mathrm{P})}, \mathrm{MC}_{(\mathrm{W})}, \mathrm{C} \Delta_{(\mathrm{W})}, \mathrm{C} \Delta_{(\mathrm{P})}$ was derived by their corresponding design values of $\mathrm{FEF}_{\mathrm{W}}, \mathrm{FEM}_{\mathrm{W}}, \mathrm{FEF}_{\mathrm{P}}, \mathrm{FEM}_{\mathrm{P}}$, $\Delta_{(\mathrm{W})}, \Delta_{(\mathrm{P})}$, respectively. These estimation coefficients $\mathrm{FC}_{(\mathrm{W})}, \mathrm{MC}_{(\mathrm{W})}, \mathrm{FC}_{(\mathrm{P})}$, $\mathrm{MC}_{(\mathrm{W})}, \mathrm{C} \Delta_{(\mathrm{W})}$ and $\mathrm{C} \Delta_{(\mathrm{P})}$ are the functions of the haunch depth ratios and are proposed for different haunch depth ratios of varying $R$ in the range of 0.0 to 4.0 with 0.2 increments. All of the estimation coefficients were obtained from the $\mathrm{FE}$ analyses, and the linear interpolation can be done between $\mathrm{FC}_{(\mathrm{W})}, \mathrm{MC}_{(\mathrm{W})}, \mathrm{FC}_{(\mathrm{P})}$, $\mathrm{MC}_{(\mathrm{W})}, \mathrm{C} \Delta_{(\mathrm{W})}$ and $\mathrm{C} \Delta_{(\mathrm{P})}$ values. It is also worth mentioning that the estimation coefficients are dimensionless, and the consistent units as given in this paper should be used for their applications. The proposed eqns. (1)-(7) can be used to 
obtain more rigorous estimates of the fixed-end reactions and the mid-span deflections without necessitating any FE analysis. The proposed method directly gives the design values without performing any additional calculation.

The fixed-end forces $\left(\mathrm{FEF}_{\mathrm{W}}\right)$ and the fixed-end moments $\left(\mathrm{FEM}_{\mathrm{W}}\right)$ at the ends of the single span historic bridges due to uniformly distributed vertical loadings (w) are given in eqn. (1) and eqn. (2), respectively:

$$
\begin{gathered}
\mathrm{FEF}_{\mathrm{W}}=\mathrm{FC}_{(\mathrm{W})} \times \mathrm{W} \times \mathrm{L} \\
\mathrm{FEM}_{\mathrm{W}}=\mathrm{MC}_{(\mathrm{W})} \times \mathrm{W} \times \mathrm{L}^{2}
\end{gathered}
$$

where $\mathrm{FC}_{(\mathrm{W})}$ and $\mathrm{MC}_{(\mathrm{W})}$ are the dimensionless estimation coefficients for the respective calculation of $\mathrm{FEF}_{\mathrm{W}}$ and $\mathrm{FEM}_{\mathrm{W}}$ due to uniformly distributed vertical loads. The values of $\mathrm{FC}_{(\mathrm{W})}$ and $\mathrm{MC}_{(\mathrm{W})}$ are given as the functions of the haunch depth ratios in table 1 .

The fixed-end forces $\left(\mathrm{FEF}_{\mathrm{P}}\right)$ and the fixed-end moments $\left(\mathrm{FEM}_{\mathrm{P}}\right)$ at the ends of the single span historic bridges due to the point load (P) at the mid-span are given in eqn. (3) and eqn. (4), respectively:

$$
\begin{aligned}
\mathrm{FEF}_{\mathrm{P}} & =\mathrm{FC}_{(\mathrm{P})} \times \mathrm{P} \times \mathrm{L} \\
\mathrm{FEM}_{\mathrm{P}} & =\mathrm{MC}_{(\mathrm{P})} \times \mathrm{P} \times \mathrm{L}
\end{aligned}
$$

where $\mathrm{FC}_{\mathrm{P}}$ and $\mathrm{MC}_{\mathrm{P}}$ are the dimensionless estimation coefficients for calculating $\mathrm{FEF}_{\mathrm{P}}$ and $\mathrm{FEM}_{\mathrm{P}}$ respectively which occur due to the point load at the mid-span (P). The values of $\mathrm{FC}_{(\mathrm{P})}$ and $\mathrm{MC}_{(\mathrm{P})}$ are given as the functions of the haunch depth ratios in table 1.

The mid-span vertical deflections $\left(\Delta_{\mathrm{W}}\right)$ of the single span historic bridges due to uniformly distributed vertical loading (w) are given in eqn. (6).

$$
\Delta_{\mathrm{W}}=\frac{1}{\Delta \mathrm{C}_{(\mathrm{W})}} \times \frac{\mathrm{w} \times \mathrm{L}^{4}}{\mathrm{EI}}
$$

where, $\mathrm{E}$ is the modulus of elasticity of the material, $\mathrm{I}$ is the moment of inertia, $\Delta \mathrm{C}_{(\mathrm{W})}$ is the dimensionless estimation coefficient for calculating the mid-span deflection due to uniformly distributed vertical loads (w). The values of $\Delta \mathrm{C}_{(\mathrm{W})}$ are given as the functions of the haunch depth ratios in table 2 .

The mid-span vertical deflections $\left(\Delta_{\mathrm{P}}\right)$ of the single span historic bridges due to point load at the mid-span (P) are given in eqn. (7).

$$
\Delta_{\mathrm{P}}=\frac{1}{\Delta \mathrm{C}_{(\mathrm{P})}} \times \frac{\mathrm{P} \times \mathrm{L}^{3}}{\mathrm{EI}}
$$

where $\Delta \mathrm{C}_{(\mathrm{P})}$ is the dimensionless estimation coefficient for calculating the midspan deflection due to point load at the mid-span (P). The values of $\Delta \mathrm{C}_{(\mathrm{P})}$ are given as the functions of the haunch depth ratios in table 2. 
Table 1: $\quad$ Fixed-end forces, fixed-end moments and the dimensionless estimation coefficients of the single span historic bridges due to uniformly distributed loads (w) and point loads at mid-span (P).

\begin{tabular}{|c||c|c|c|c||c|c|c|c|}
\hline \multirow{2}{*}{$\mathrm{R}$} & \multicolumn{2}{|c||}{ Uniformly Distributed Load $(\mathrm{w})$} & \multicolumn{3}{c|}{ Point Load at Mid-span $(\mathrm{P})$} \\
\cline { 2 - 9 } & $\mathrm{FEF}$ & $\mathrm{FEM}$ & $\mathrm{FC}_{(\mathrm{W})}$ & $\mathrm{MC}_{(\mathrm{W})}$ & $\mathrm{FEF}$ & $\mathrm{FEM}$ & $\mathrm{FC}_{(\mathrm{P})}$ & $\mathrm{MC}_{(\mathrm{P})}$ \\
\hline \hline 0.0 & 0.000 & 8.362 & 0.0000 & 0.0836 & 0.000 & 12.424 & 0.0000 & 0.1242 \\
\hline 0.2 & 1.267 & 8.870 & 0.1267 & 0.0887 & 2.173 & 13.459 & 0.2173 & 0.1346 \\
\hline 0.4 & 1.847 & 9.132 & 0.1847 & 0.0913 & 3.490 & 13.984 & 0.3490 & 0.1398 \\
\hline 0.6 & 2.217 & 9.245 & 0.2217 & 0.0924 & 4.321 & 14.220 & 0.4321 & 0.1422 \\
\hline 0.8 & 2.408 & 9.267 & 0.2408 & 0.0927 & 4.842 & 14.269 & 0.4842 & 0.1427 \\
\hline 1.0 & 2.517 & 9.233 & 0.2517 & 0.0923 & 5.167 & 14.197 & 0.5167 & 0.1420 \\
\hline 1.2 & 2.566 & 9.165 & 0.2566 & 0.0917 & 5.381 & 14.045 & 0.5381 & 0.1404 \\
\hline 1.4 & 2.578 & 9.076 & 0.2578 & 0.0908 & 5.482 & 13.837 & 0.5482 & 0.1384 \\
\hline 1.6 & 2.568 & 8.973 & 0.2568 & 0.0897 & 5.545 & 13.592 & 0.5545 & 0.1359 \\
\hline 1.8 & 2.543 & 8.861 & 0.2543 & 0.0886 & 5.571 & 13.319 & 0.5571 & 0.1332 \\
\hline 2.0 & 2.513 & 8.744 & 0.2513 & 0.0874 & 5.573 & 13.029 & 0.5573 & 0.1303 \\
\hline 2.2 & 2.476 & 8.624 & 0.2476 & 0.0862 & 5.559 & 12.723 & 0.5559 & 0.1272 \\
\hline 2.4 & 2.438 & 8.501 & 0.2438 & 0.0850 & 5.535 & 12.406 & 0.5535 & 0.1241 \\
\hline 2.6 & 2.399 & 8.378 & 0.2399 & 0.0838 & 5.503 & 12.082 & 0.5503 & 0.1208 \\
\hline 2.8 & 2.360 & 8.253 & 0.2360 & 0.0825 & 5.467 & 11.751 & 0.5467 & 0.1175 \\
\hline 3.0 & 2.323 & 8.129 & 0.2323 & 0.0813 & 5.429 & 11.418 & 0.5429 & 0.1142 \\
\hline 3.2 & 2.286 & 8.004 & 0.2286 & 0.0800 & 5.388 & 11.079 & 0.5388 & 0.1108 \\
\hline 3.4 & 2.250 & 7.880 & 0.2250 & 0.0788 & 5.347 & 10.739 & 0.5347 & 0.1074 \\
\hline 3.6 & 2.216 & 7.756 & 0.2216 & 0.0776 & 5.306 & 10.396 & 0.5306 & 0.1040 \\
\hline 3.8 & 2.184 & 7.633 & 0.2184 & 0.0763 & 5.265 & 10.052 & 0.5265 & 0.1005 \\
\hline 4.0 & 2.152 & 7.510 & 0.2152 & 0.0751 & 5.225 & 9.706 & 0.5225 & 0.0971 \\
\hline
\end{tabular}

\section{Summary and conclusions}

In this paper, the linear elastic behaviour of the single span $\mathrm{RC}$ historic bridges subjected to vertical loading conditions were investigated by plane stress FE analyses considering the thrust effects. The parametric studies were performed for the single span historic bridges with $\mathrm{b}=0.5 \mathrm{~m}, \mathrm{~h}=1 \mathrm{~m}, \mathrm{~L}=10 \mathrm{~m}$ and having haunch depth ratios $(\mathrm{R})$ varying in the range of 0.0 to 4.0 with an interval of 0.1 and for the haunch length ratio of $\alpha=0.5$ using realistic theoretical models. An 
Table 2: Mid-span deflections and the dimensionless estimation coefficients due to uniformly distributed load (w) and point load at mid-span (P).

\begin{tabular}{|c|c|c|c|c|}
\hline \multirow[b]{2}{*}{$\mathrm{R}$} & \multicolumn{2}{|c|}{$\mathrm{w}(\mathrm{kN} / \mathrm{m})$} & \multicolumn{2}{|c|}{$\mathrm{P}(\mathrm{kN})$} \\
\hline & $\Delta_{\mathrm{W}}(\mathrm{mm})$ & $\Delta \mathrm{C}_{(\mathrm{w})}$ & $\Delta_{\mathrm{p}}(\mathrm{mm})$ & $\Delta \mathrm{C}_{(\mathrm{P})}$ \\
\hline 0.0 & 0.02319 & 345.0 & 0.04572 & 175.0 \\
\hline 0.2 & 0.01795 & 445.7 & 0.03674 & 217.7 \\
\hline 0.4 & 0.01424 & 561.8 & 0.03014 & 265.4 \\
\hline 0.6 & 0.01157 & 691.4 & 0.02524 & 317.0 \\
\hline 0.8 & 0.00961 & 832.3 & 0.02155 & 371.2 \\
\hline 1.0 & 0.00814 & 982.4 & 0.01871 & 427.6 \\
\hline 1.2 & 0.00702 & 1139.9 & 0.01650 & 484.8 \\
\hline 1.4 & 0.00614 & 1302.9 & 0.01473 & 543.1 \\
\hline 1.6 & 0.00544 & 1470.0 & 0.01330 & 601.5 \\
\hline 1.8 & 0.00488 & 1639.7 & 0.01213 & 659.5 \\
\hline 2.0 & 0.00442 & 1811.2 & 0.01115 & 717.5 \\
\hline 2.2 & 0.00403 & 1983.6 & 0.01032 & 775.2 \\
\hline 2.4 & 0.00371 & 2155.8 & 0.00962 & 831.6 \\
\hline 2.6 & 0.00344 & 2327.6 & 0.00901 & 887.9 \\
\hline 2.8 & 0.00320 & 2498.4 & 0.00849 & 942.3 \\
\hline 3.0 & 0.00300 & 2667.6 & 0.00803 & 996.3 \\
\hline 3.2 & 0.00282 & 2834.9 & 0.00762 & 1049.9 \\
\hline 3.4 & 0.00267 & 2999.6 & 0.00726 & 1101.9 \\
\hline 3.6 & 0.00253 & 3163.3 & 0.00694 & 1152.7 \\
\hline 3.8 & 0.00241 & 3323.6 & 0.00665 & 1203.0 \\
\hline 4.0 & 0.00230 & 3482.8 & 0.00639 & 1252.0 \\
\hline
\end{tabular}

extensive parametric study was conducted and the fixed-end reactions and mid-span deflections due to vertical loading conditions were computed by $\mathrm{FE}$ analyses. $\mathrm{FEF}_{\mathrm{W}}, \mathrm{FEM}_{\mathrm{W}}, \mathrm{FEF}_{\mathrm{P}}, \mathrm{FEM}_{\mathrm{P}}, \Delta_{\mathrm{W}}$ and $\Delta_{\mathrm{P}}$ values were calculated for the single span RC historic bridges having various haunch depth ratios (R). Based on results of FE analyses carried, the design formulas (eqs. (1)-(7)) and the design coefficients (tables 1,2) were proposed to be able to compute the fixed-end reactions and mid-span deflections without necessitating any additional $\mathrm{FE}$ analyses. The design coefficients were separately proposed as the functions of the haunch depth ratios $(\mathrm{R})$. The formulation considers the dimensions of the rectangular cross-section of the non-prismatic members, the discontinuity of the centroidal axis, the local stress concentrations, the nonlinear stress distributions and the existence of the null areas that reduces the member stiffness. 


\section{Acknowledgement}

The research reported herein was supported by grants from the Scientific and Technical Research Council of Turkey (TÜBİTAK-107M639).

\section{References}

[1] Portland Cement Association (PCA), Beam factors and moment coefficients for members of variable cross-section. Handbook of frame constants, Chicago. 1958.

[2] Hibbeler, R., Structural analysis, Fifth Edition. Prentice-Hall Inc., Upper Saddle River, New Jersey, 2002.

[3] Tartaglione, L.C., Structural Analysis, McGraw-Hill, Ins, New York, United States of America, pp. 412-427, 1991.

[4] El-Mezaini, N., Balkaya, C. \& Citıpıoglu, E., Analysis of frames with nonprismatic members. Journal of Structural Engineering, ASCE, 117 (6), pp. 1573-1592, 1991.

[5] Balkaya, C., Behaviour and modelling of nonprismatic members having Tsections. ASCE Journal of Structural Engineering. 127(8), pp. 940-946, 2003.

[6] CSI, 2007. Computer and Structures Inc. SAP2000 User's Manual. Berkeley, CA, 2007, www.csiberkeley.com.

[7] Bathe, K.J., Finite Element Procedures, Prentice Hall Publisher: NJ, USA, 1996.

[8] Horrowitz, B., Singularities in elastic finite element analysis. Concrete International, December: pp. 33-36, 1997.

[9] Balkaya C., Kalkan E. \& Yuksel S.B., FE analysis and practical modelling of RC multi-bin circular silos. ACI Structural journal, 103(3), pp. 365-371, 2006.

[10] Yuksel, S.B., Slit Connected Coupling Beams for Tunnel Form Building Structures. The Structural Design of Tall and Special Buildings, 17(3), pp. 579-600, 2008.

[11] Yuksel, S. B. \& Arikan, S., A new set of design aids for groups of four cylindrical silos due to interstice and internal loadings, The Structural Design of Tall and Special Buildings, 18(2), pp. 149-169, 2009.

[12] Yuksel, S. B., Behaviour of symmetrically haunched non-prismatic members subjected to temperature changes. Structural Engineering \& Mechanics, 31(3), pp. 297-314, 2009. 